\title{
Unemployment compensation and aggregate fluctuations
}

\author{
Christian Glocker
}

Received: 2 December 2010/ Accepted: 20 September 2011/Published online: 20 October 2011

(C) Springer-Verlag 2011

\begin{abstract}
This paper focuses on a theoretical and empirical analysis of the effects of discretionary changes of unemployment compensation payments on aggregate fluctuations. By means of a dynamic stochastic general equilibrium model, it is shown that unemployment compensation can stabilize consumption on the one hand; however, on the other one, it has adverse effects on unemployment and output. These theoretical results are confirmed by the empirical structural vector autoregressive model. Moreover, the results highlight the importance of real wages in transmitting unemployment benefit shocks on to the macroeconomy. In particular, discretionary changes lead to an increase in real wages, unemployment and consumption while inducing a small decline in output.
\end{abstract}

Keywords DSGE models · Fiscal policy · Unemployment insurance

JEL Classification E3 $\cdot$ E62 $\cdot$ J65

\section{Introduction}

The importance of discretionary changes in government consumption and taxes for economic fluctuations is well understood, see for instance Galí, López-Salido and

\footnotetext{
I thank Christian Kleiber, Thiago Abdala, Tomaz Cajner, Stefan Csordás, Silvio Petriconi, Tikesh Ramtohul, Gregor Reich and Pascal Towbin for helpful comments and discussions. Two anonymous referees and an associate editor provided valuable suggestions that substantially improved this paper. I also thank seminar audiences at the Universität Basel, the Universität Wien and the Humboldt Universität zu Berlin for helpful comments. All remaining errors are my own.

C. Glocker $(\bowtie)$

Department for Quantitative Methods, Universität Basel, Wirtschaftswissenschaftliches Zentrum (WWZ), Peter Merian-Weg 6, 4002 Basel, Switzerland

e-mail: c.glocker@unibas.ch; christian.glocker@banque-france.fr
} 
Vallés (2007), Mountford and Uhlig (2008), Blanchard and Perotti (2002) for empirical evidence and Baxter and King (1993), Chari et al. (1994) and Chari and Kehoe (1999) for theoretical work. However, the government can affect economic fluctuations also by other instruments of which an important one is the publicly provided social insurance program. This program has increasingly attracted the attention of research. Past research, however, either has put all these sources of governmental impact into one overall variable to elaborate on the macroeconomic effects of fiscal policy or has been directed toward estimating program specific effects on the microeconomic level. So far, the investigation into the macroeconomic effects of specific public social programs has been left untouched.

In the United States, the unemployment insurance program constitutes one of the major social security systems. It provides payments and income protection for those who have involuntarily lost their jobs. During normal times, unemployment benefit payments are provided through the regular unemployment compensation program, which is administered and funded at the state level. Regular benefit payments occur on a weekly basis and replace $50-80 \%$ of the pre-unemployment earnings. In the majority of the states, this insurance lasts for 26 weeks. During economic downturns, however, the federal government often provides additional support by extending unemployment insurance benefits-both the duration as well as the replacement rate. The US government has repeatedly made use of this practice in order to combat the surmounting joblessness. For instance, within the last financial crisis, unemployed workers who reside in states with relatively high unemployment rates are entitled to receive unemployment insurance benefits up to 99 weeks, that is, 26 weeks of regular payments and 73 weeks of extended benefits ${ }^{1}$ (see for instance Fujita 2010; Whittaker 2008; Whittaker and Isaacs 2011a, b; Whittaker et al. 2011).

Given the painful nature of job losses, the merits of unemployment compensation benefits are often taken for granted in public discussions, in particular, because as an insurance against unemployment, they provide welfare gains to those workers who lost their jobs. However, the question which arises immediately is: are these gains produced at a cost since they induce a redistribution of resources away from their efficient use? Hence, the study of unemployment benefits is important for at least two reasons. First, they affect not just a single market but several ones immediately; next to their instantaneous effects along the demand side of the economy by increasing the income of unemployed people, they also have an impact on the labor market by crucially affecting the wage bargaining process between workers and firms. The second argument is related to one common question addressing fiscal policy, namely to what extent do unemployment benefits act as an accelerator of economic fluctuations? The government provides an insurance against job loss by

\footnotetext{
${ }^{1}$ In the United States, there are two types of federal emergency programs. One is called the extended benefit program which is permanently authorized, meaning that the extension is triggered automatically whenever the state unemployment rate reaches a certain level. It provides additional weeks of unemployment benefit payments up to a maximum of 13 or even 20 weeks. The second type is a federal program that the Congress enacts temporarily during economic downturns. The Congress has repeatedly implemented these federal emergency programs. These programs typically provided benefits for a total of around 60 weeks.
} 
means of unemployment compensation payments. There is, however, a concern that it might produce an adverse effect on the incentive to look for a job. That is, unemployment insurance could cause job seekers to put less effort into searching for a job, consequently raising the unemployment rate. Now, if the government provides additional support by extending unemployment insurance benefits in economic downturns, then the unemployment insurance system could severely increase the persistence as well as the level of unemployment. The important thing to notice is that in the latter case, the government implements discretionary policy: it carries out expansionary fiscal policy by extending the regular unemployment compensation program. These discretionary changes are at the core of the current analysis.

On their own, unemployment benefits have been analyzed in great depth at the microeconomic level. Studies by Gruber (1997), Hamermesh (1992) and Browning and Crossley (2001), to mention a few, find that there is strong evidence that unemployment benefits smooth individual consumption and that the magnitude of such consumption smoothing is nontrivial. They emphasize the importance of unemployment insurance provided by the government due to both adverse selection problems with private unemployment insurance systems and potential capital market constraints faced by workers who try to smooth their lifetime consumption. Thus, publicly provided unemployment insurance may raise welfare by filling the missing market for a state-contingent payment (Gruber 1997). Apart from the effects of unemployment benefits on individual consumption, research has also focused on the effects of the duration of unemployment on an individual's decision whether to work or rather draw unemployment benefits. Nickell (1979), Lancaster (1979) and Atkinson and Micklewright (1991), to mention a few, found that higher benefits are associated with longer unemployment spells. However, there is criticism to this finding since, as Pellizzari (2005) argues, changes in the generosity of unemployment benefits have no significant effect on the level or duration of unemployment.

Regarding their macroeconomic influences, Hamermesh (1992), Auerbach and Feenberg (2000) and Dunson et al. (1991) among others emphasize their importance as a source of automatic stabilizer. Keynesian macroeconomics argues that the automatic increase in benefit payments that accompanies cyclical declines in aggregate demand will at least partly maintain consumer confidence spending and hence dampen the reduction in aggregate demand. Apart from this stabilizing effect, Hamermesh (1992) argued that aggregate output might be affected negatively from unemployment insurance programs since these programs shift resources away from their efficient use. The argument is that unemployment insurance programs subsidize risky activities which leads to their relative expansion. At the margin, resources are diverted from their best uses such that aggregate output is diminished.

This paper seeks to understand the discretionary effects of changes in unemployment compensation, both from an empirical and from a theoretical perspective. The theoretical part is motivated by a standard dynamic stochastic general equilibrium (DSGE) model comprising the New Keynesian and the Diamond-Mortensen-Pissarides model. The analysis considers unemployment 
benefit payments both from an exogenous definition and from an endogenous one. The results show that higher unemployment benefit payments affect consumption positively on the one hand; however, on the other hand, they trigger negative effects on output and unemployment. These findings are supported by the empirical model. Specifically, I specify a structural vector autoregressive (SVAR) model using, among others, consumption, the real wage, aggregate output and unemployment as core variables. Based on the identification of a surprise innovation in unemployment benefits, I trace out the effects on aggregate variables triggered by discretionary changes in unemployment compensation. The results suggest that after an expansionary shock unemployment and real wages respond in a hump-shaped pattern peaking after about one and a half years, output responds in a hump-shaped pattern too; however, it reaches a trough after about two and a half years. Moreover, consumption increases and falls back to its preshock value after about three years. The policy shock accounts for a nontrivial fraction of the variation in unemployment, real wages and consumption.

The outline of the paper is as follows. Section 2 motivates the DSGE model and discusses the theoretical results. Section 3 presents the empirical part and ends with a discussion of the nature of the shock. Finally, Sect. 4 concludes.

\section{The DSGE model}

This section motivates the effects of changes in unemployment benefit payments by means of a small dynamic stochastic general equilibrium (DSGE) model. The present model is a standard New Keynesian model augmented with the DiamondMortensen-Pissarides model.

Following Gertler and Trigari (2009) and Gertler et al. (2008), I only allow for an adjustment along the extensive margin in the labor market.

The economy consists of households, a continuum of wholesale firms which produce differentiated intermediate goods, the retail firms, a fiscal authority and a central bank in charge of monetary policy.

\subsection{The household sector}

There is a continuum of agents with mass unity who consume different varieties of goods and save. Each agent can be either employed or unemployed. Once employed, the consumer supplies one unit of labor in-elastically and receives labor income; if not employed, he receives unemployment benefits.

Households maximize the following expected lifetime utility: $E_{t}\left[\sum_{\tau \geq t} \beta^{\tau} \ln \left(C_{\tau}\right)\right]$, where $C_{t}$ denotes consumption of final goods and $\beta$ is the discount factor. For employed household members $\left(n_{t}\right)$, total real labor income net of labor taxes is given by $(1-\tau) W_{t} n_{t}$, where $W_{t}$ denotes the real wage and $\tau$ is the labor tax rate. Each unemployed household member $\left(U_{t}\right)$ receives unemployment benefits $\Gamma_{t}$. Let $D_{t}$ be lump sum profits, $B_{t}$ nominal riskless bonds and $R_{t}$ the gross nominal return on bonds, then the budget constraint is: 


$$
P_{t} C_{t}+R_{t}^{-1} B_{t}=B_{t-1}+P_{t}\left[(1-\tau) W_{t} n_{t}+\Gamma_{t} U_{t}\right]+D_{t}
$$

Households maximize lifetime utility subject to the budget constraint which yields the following intertemporal optimality condition: $1=E_{t}\left[\Lambda_{t, t+1} \frac{R_{t}}{\pi_{t+1}}\right]$, where $\Lambda_{t, t+s}$ is the stochastic discount factor: $\Lambda_{t, t+s} \equiv \beta^{s} \frac{C_{t+s}}{C_{t}}$ and $\pi_{t}$ is the gross inflation rate.

\subsection{Matching of vacancies and unemployment}

There is a continuum of intermediate goods producing firms indexed by $i \in[0,1]$. They post vacancies in order to attract unemployed workers and employ workers. The amount of employed workers is $n_{t}=\int_{0}^{1} n_{t}(i) \mathrm{d} i$ and aggregate vacancies are given by $V_{t}=\int_{0}^{1} V_{t}(i) \mathrm{d} i$. Each employed worker supplies a fixed amount of hours worked and unemployed workers search for jobs. The timing assumption is such that in case an unemployed worker matches with a vacancy, he starts to work immediately. This implies that the pool of unemployed people searching for a job is given by the difference between the total labor force which is normalized to unity and the amount of employed people: $U_{t}=1-n_{t}$

The function matching unemployed workers and firms with a vacancy is:

$$
m_{t}=U_{t}^{\zeta_{m}} V_{t}^{1-\zeta_{m}}
$$

$\zeta_{m}$ is the elasticity of unemployment in the matching technology and the total amount of matches in period $t$ is given by $m_{t}$. Let $q_{t}$ denote the probability of a vacancy being filled in period $t$ by defining

$$
q_{t}=\frac{m_{t}}{V_{t}}=\left(\frac{V_{t}}{U_{t}}\right)^{-\zeta_{m}}=\vartheta_{t}^{-\zeta_{m}}
$$

where $\vartheta_{t}:=\frac{V_{t}}{U_{t}}$ measures the degree of labor market tightness. Similarly, $p_{t}$ is the probability a searching worker finds a job and is given by: $p_{t}=\vartheta_{t} \cdot q_{t}$

Firms and workers take $q_{t}$ and $p_{t}$ as given. Finally, each period firms separate from a fraction $s$ of their current workforce $n_{t-1}(i)$. Once a worker loses his job, he is not allowed to search until the next period. This restriction implies that fluctuations are triggered by cyclical variations in hiring rather than due to fluctuations in separations.

\subsection{Wholesale firms}

Production takes place in the wholesale firms. They hire workers and negotiate wage contracts with them. Following Ebell and Haefke (2009), I refrain from the one-worker-one-firm assumption in favor of a more general framework with multiple worker-firm pairings. The production of a typical wholesale firm depends on the amount of workers hired. When firms chose employment, they take the real wage as given. The firm considers the workers as identical and the output produced in firm $i$ at time $t$ is: $y_{t}(i)=\xi_{t}^{A} n_{t}(i)$, where $\xi_{t}^{A}$ represents total factor productivity. 
Wholesale firms solve a profit maximization problem based on the following expected stream of revenues net of expenses: $E_{t}\left[\sum_{s=0}^{\infty} \Lambda_{t, t+s}\left(\mu_{t}(i) \xi_{t}^{A} n_{t+s}(i)\right.\right.$ $\left.\left.-W_{t+s} n_{t+s}(i)-c_{v} V_{t+s}(i)\right)\right]$, where $\Lambda_{t, t+1}$ is the households' stochastic discount factor defined in Sect. $2.1^{2}, c_{v}$ are the costs per vacancy associated with posting vacancies and $W_{t}$ is the real wage. The employment flow equation of firm $i$ is given by: $n_{t}(i)=(1-s) n_{t-1}(i)+q_{t} V_{t}(i)$.

At each point in time, a firm maximizes its profits by choosing the work force and the amount of vacancies posted. The first-order conditions of the firm's optimization problem yield the following job creation condition:

$$
\frac{c_{v}}{q_{t}}=E_{t}\left[\Lambda_{t, t+1}\left(\xi_{t+1}^{A} \mu_{t+1}(i)-W_{t+1}(i)+(1-s) \frac{c_{v}}{q_{t+1}}\right)\right]
$$

Equation 4 equates the expected return of creating a new job, expressed by the right hand side, to the cost of vacancy creation. The cost of creating a vacancy is given by the expected duration it takes to fill a vacancy $\left(1 / q_{t}\right)$ times the associated costs per vacancy $\left(c_{v}\right)$.

\subsection{Wage bargaining}

The matching friction gives rise to a bilateral monopoly context. There are rents to be split when workers and wholesale firms meet: if one party turns down a wage offer, finding another potential partner is costly. I proceed by following Pissarides (2000), Mortensen and Pissarides (1994) and Ebell and Haefke (2009) by applying the Nash bargaining solution. In this framework, the bargained real wage $\left(W_{t}\right)$ is determined as the outcome of a Nash bargaining between workers and firms.

Each household member can be either employed or unemployed. Agent is value function of these two states satisfies

$$
\begin{gathered}
Y_{t}^{E}(i)=(1-\tau) W_{t}+E_{t}\left[\Lambda_{t, t+1}\left((1-s) Y_{t+1}^{E}(i)+s Y_{t+1}^{U}(i)\right)\right] \\
Y_{t}^{U}(i)=\Gamma_{t}+E_{t}\left[\Lambda_{t, t+1}\left(p_{t+1} Y_{t+1}^{E}(i)+\left(1-p_{t+1}\right) Y_{t+1}^{U}(i)\right)\right]
\end{gathered}
$$

where $Y_{t}^{E}$ and $Y_{t}^{U}$ represent the value of employment and unemployment. The value of unemployment depends on the current flow value $\Gamma_{t}$ and the likelihood of being employed versus unemployed in the next period. $\Gamma_{t}$ will be discussed in more detail in Sect. 2.6

The value function of firm $i$ is: $J_{t}(i)=\xi_{t}^{A} \mu_{t}(i)-W_{t}+(1-s) E_{t}\left[\Lambda_{t, t+1} J_{t+1}(i)\right]$ and the free entry condition implies that $\frac{c_{v}}{q_{t}}=E_{t}\left[\Lambda_{t, t+1} J_{t+1}(i)\right]$. Bargaining takes place over the real wage $\left(W_{t}\right)$ and the aggregate price level $\left(P_{t}\right)$ is taken as given. The equilibrium real wage is derived from the maximization of the following Nash product: $\max _{W}\left(Y^{E}(i)-Y^{U}(i)\right)^{1-\eta} \cdot J(i)^{\eta}$, where $\eta \in(0,1)$ measures the bargaining power of each party. The first-order condition implies the following expression for the real wage

\footnotetext{
${ }^{2}$ Since households are the owners of firms, profits are evaluated in terms of value attached to them.
} 


$$
W_{t}=\frac{1-\eta}{1-\tau} \Gamma_{t}+\eta\left(\xi_{t}^{A} \mu_{t}+c_{v} \vartheta_{t}\right)
$$

The result is intuitive: the real wage a worker gets is increasing in unemployment benefits $\left(\Gamma_{t}\right)$, the relative bargaining strength of the worker $(1-\eta)$, the tightness in the labor market and the tax rate on labor income.

\subsection{Retailers}

Retailers are monopolistic competitors and set prices for their goods to be sold in the product market in a staggered fashion. They buy the intermediate goods from the wholesale firms and differentiate them with a technology that transforms one unit of intermediate good into one unit of retail good and then re-sell these transformed goods to households as consumption goods.

The final good is produced by a representative firm using a CES production function with elasticity of substitution $\epsilon$ to aggregate a continuum of intermediate goods indexed by $Y_{t}=\left(\int_{0}^{1} y_{t}(i)^{\frac{\epsilon-1}{\epsilon}} \mathrm{d} i\right)^{\frac{\epsilon}{\epsilon-1}}$. Final goods producers operate in competitive markets and maximize each period the following stream of profits $P_{t} Y_{t}-$ $\int_{0}^{1} p_{t}(i) y_{t}(i) \mathrm{d} i$ where $p_{t}(i)$ is the price of intermediate good $i$. The demand for each intermediate input good is $y_{t}(i)=\left(p_{t}(i) / P_{t}\right)^{-\epsilon} \cdot Y_{t}$ and the aggregate price level satisfies $P_{t}=\left(\int_{0}^{1} p_{t}(i)^{1-\epsilon} \mathrm{d} i\right)^{\frac{1}{1-\epsilon}}$.

I assume that Calvo-type price staggering (Calvo 1983) applies to the price setting behavior of retailers. The probability that a firm cannot re-optimize its price for $k$ periods is given by $\theta^{k}$. Profit maximization by a retailer who is allowed to reoptimize his price at time $t$ chooses a target price $p_{t}^{*}$ to maximize the following stream of future profits: $\max _{p_{t}^{*}} E_{t}\left[\sum_{k=0}^{\infty} \theta^{k} \Lambda_{t, t+k}\left(\frac{p_{t}^{*}}{P_{t+k}} \cdot y_{t+k \mid t}(i)-C o_{t+k}\left(y_{t+k \mid t}(i)\right)\right)\right]$ for which the first-order condition is

$$
E_{t}\left[\sum_{k=0}^{\infty} \theta^{k} \Lambda_{t, t+k} y_{t+k \mid t}(i)\left(\frac{p_{t}^{*}}{P_{t+k}}-\frac{\epsilon}{\epsilon-1} \mu_{t+k \mid t}(r)\right)\right]=0
$$

where $C o_{t+k \mid t}^{\prime}\left(Y_{t+k \mid t}(r)\right)=\mu_{t+k \mid t}(r)$ are marginal costs.

\subsection{Fiscal and monetary policy}

Monetary policy is modeled by a simple Taylor type rule of the following form: $\frac{R_{t}}{R}=\pi_{t}^{\phi_{\pi}}$, where $R$ is the steady-state value of $R_{t}$. The fiscal authority's budget constraint satisfies

$$
\tau W_{t} N_{t}+R_{t}^{-1} B_{t}^{*}=\frac{B_{t-1}^{*}}{\pi_{t}}+U_{t} \Gamma_{t}
$$

where real government bonds satisfy $B_{t}^{*}=B_{t} / P_{t} . \Gamma_{t}$ is the amount of unemployment benefits given to an unemployed worker as outlined in Sects. 2.1 and 2.4. Hence, the total amount of expenditures due to unemployment benefit payments is 
$U_{t} \Gamma_{t}$. In the present model, the fiscal authority controls unemployment benefits by making use of the following fiscal policy rule (expressed in log-deviations from the corresponding steady states)

$$
\hat{\Gamma}_{t}=\phi_{\Gamma} \hat{\Gamma}_{t-1}+\left(1-\phi_{\Gamma}\right) \phi_{U} \hat{U}_{t}+\epsilon_{t}^{\Gamma} \quad \text { where } \epsilon_{t}^{\Gamma} \sim\left(0, \sigma_{\Gamma}^{2}\right)
$$

It is assumed that $\phi_{\Gamma} \in[0,1)$. The baseline model is characterized by letting unemployment benefits enter the model as a complete exogenous variable following a persistent $\mathrm{AR}(1)$ process $\left(\phi_{U}=0\right)$. With $\phi_{U}>0$, one can allow for a feedback from the economy to unemployment compensation. In particular, this scenario is supposed to represent the policy steps taken by the US government as mentioned in the introduction. The extension of unemployment benefit payments in times of economic downturns is replicated in the model by $\phi_{U}>0$. Hence, unemployment benefit payments become more generous when unemployment is high.

\subsection{Calibration}

The model is calibrated at a quarterly frequency. The discount factor $\beta$ is set to 0.99 . The matching elasticity parameter $\zeta_{M}$ is fixed at 0.5 which is in line with empirical evidence surveyed in Petrongolo and Pissarides (2001). The bargaining weight for workers $1-\eta$ is set to 0.5 , and following Fujita and Ramey (2007), the steady-state unemployment rate is equal to 0.08. In line with den Haan, Ramey and Watson (2000) and Willems (2010), I fix the steady-state firm matching rate $q$ at 0.7 and the steady-state job finding rate at 0.6. This defines the steady-state labor market tightness parameter $\vartheta$ at 0.85 and the job destruction rate $s$ at 0.05 . The value for the parameter describing costs due to vacancy posting $c_{v}$ is obtained via the job creation condition and equals 0.097 .

The coefficient for inflation in the Taylor rule is set to 1.5. Following the RBC literature, the autocorrelation coefficient of the $\operatorname{AR}(1)$ process for technology $\left(\rho_{A}\right)$ is set to 0.90 and the one for unemployment benefits $\left(\phi_{\Gamma}\right)$ to $0.80^{3}$.

\subsection{Model dynamics}

The current section discusses unemployment benefits from two perspectives: Fig. 1 elaborates on the discretionary effects of changes in unemployment benefit payments, whereas Fig. 2 shows the consequences of endogenous unemployment benefits based on a technology shock.

In Fig. 1, the black solid line represents the baseline scenario where unemployment benefits $\left(\Gamma_{t}\right)$ follow an exogenous $\operatorname{AR}(1)$ process $\left(\phi_{U}=0\right)$. The immediate effect of an increase in unemployment benefits is a strong increase in the real wage. The intensity of the impact mainly depends on the relative strength of each party, that is firms and workers, within the wage negotiations. As a consequence of higher unemployment benefits, workers demand higher wages so as to still be eligible for

\footnotetext{
3 Estimating an AR(1) process for the time series of unemployment benefits, as discussed in Sect. 3, would yield a value of 0.794 for the autocorrelation coefficient.
} 

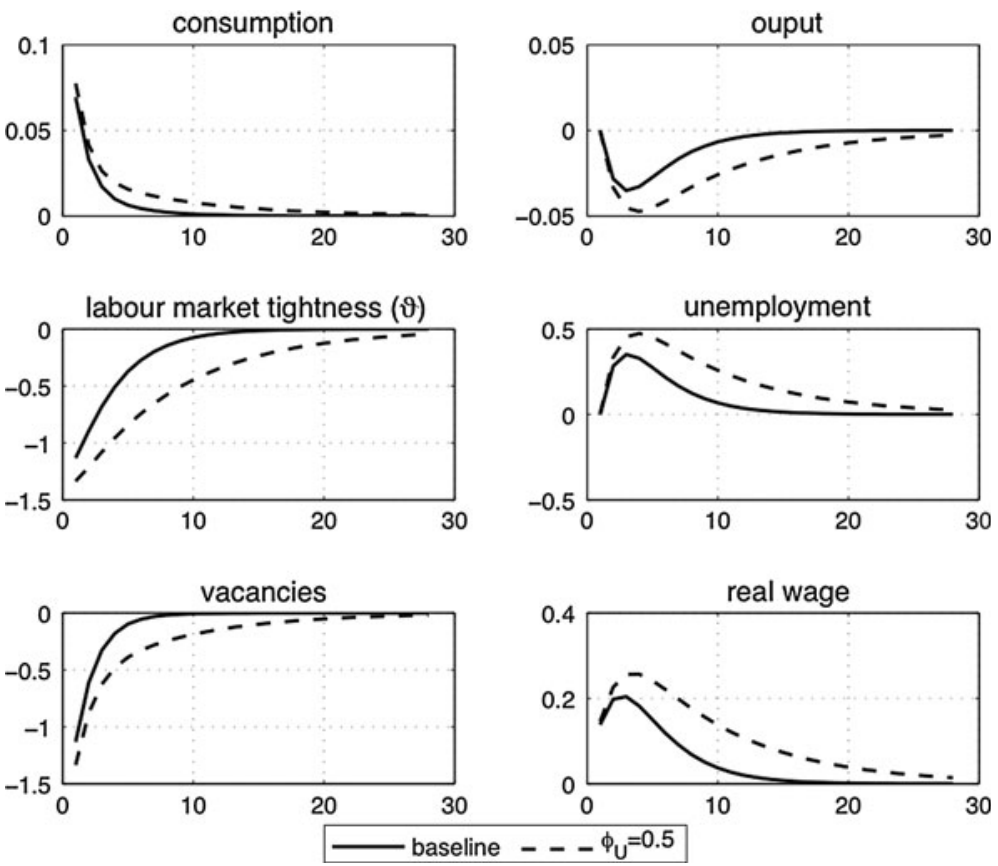

Fig. 1 Impulse response functions to a shock in unemployment benefits. In the baseline scenario, unemployment benefits follow an exogenous $\mathrm{AR}(1)$ process $\left(\phi_{U}=0\right)$. The dotted line represents a scenario where unemployment benefits react endogenously to unemployment $\left(\phi_{U}=0.5\right)$

work. The higher the workers' share within these negotiations, the stronger is the effect of an increase in unemployment compensation on the real wage.

The increase in the real wage triggers a series of effects, in particular within the production sector which the job creation condition is crucial for. An increase in the real wage decreases the expected return of creating new jobs, that is the willingness of posting vacancies shrinks. Hence, the amount of posted vacancies declines. Moreover, the shadow value of employment falls since now firms face higher costs due to a higher wage bill. As a consequence, aggregate employment declines, and since the total amount of people available for work is constant, the decrease in employment propagates into higher unemployment.

Moving on to the goods market, the strong decline in employment is transmitted into a corresponding drop in aggregate output. This is in line with Hamermesh (1992) who argues that aggregate output might be affected negatively due to increases in unemployment benefits since these programs shift resources away from their efficient use. However, usually these programs are not aimed at stabilizing output but consumption instead. As shown in Fig. 1, consumption increases strongly. The reason for the increase is due to the fact that the real interest rate declines. The fall in marginal costs triggers a decline in the inflation rate. By the Taylor principle, the decline in the inflation rate causes an even stronger fall in the nominal rate, hence inducing real rates to fall. The lower real rates boost 

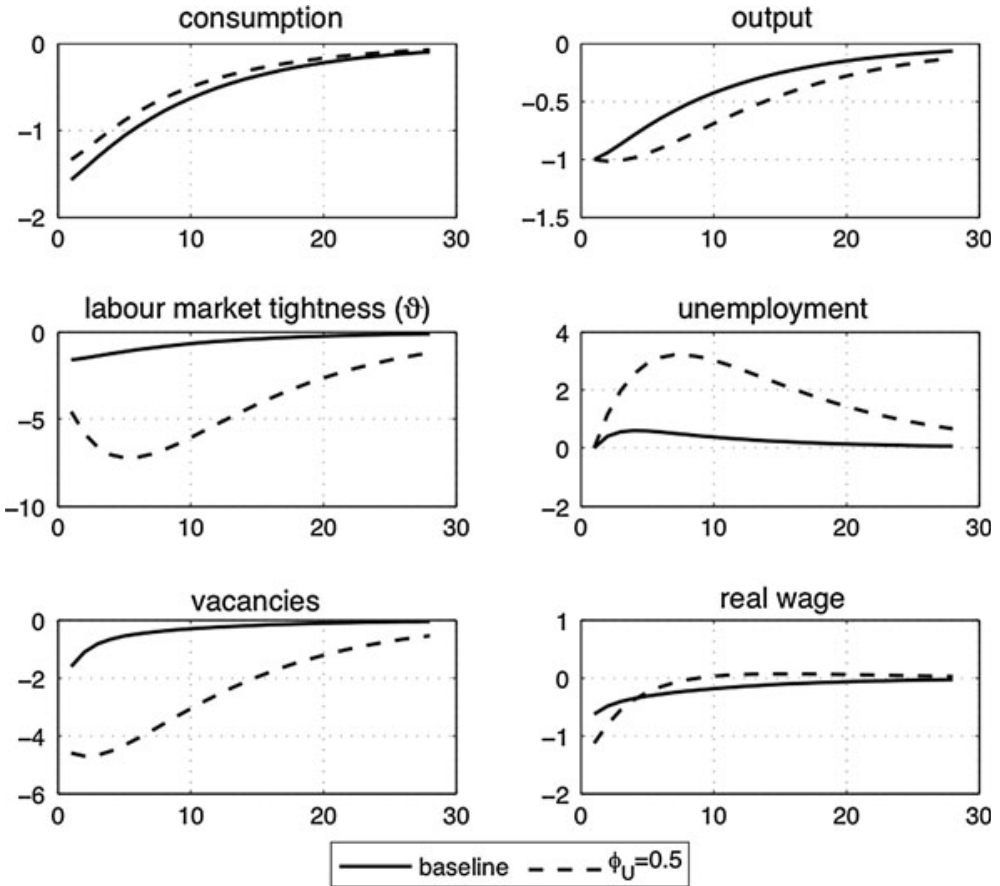

Fig. 2 Impulse response functions to a shock in technology. In the baseline scenario, unemployment benefits follow an exogenous $\operatorname{AR}(1)$ process $\left(\phi_{U}=0\right)$. The dotted line represents a scenario where unemployment benefits react endogenously to unemployment $\left(\phi_{U}=0.5\right)$

consumption. In order to understand the decline in marginal costs despite the increase in real wages, the job creation condition (Eq. 4) is once more of importance. The fall in the shadow value of employment triggers a decline in employment as well as the number of vacancies posted. This decrease outweighs the increase in real wages so that finally marginal costs decline.

Comparing this to the scenario where unemployment benefits react endogenously to changes in unemployment (shown by the dotted line in Fig. 1) indicates that the results do not change qualitatively. However, what changes is the persistence of the shock. This is due to a multiplier effect which will be explained below.

In contrast to Figs. 1 and 2 shows the consequences of a contractionary technology shock once unemployment benefit payments react endogenously to higher unemployment rates (shown by the dotted lines). The policy is such that higher unemployment increases unemployment benefit payments. This policy specification is in line with the second type of federal programs in the United States as discussed in the introduction.

The contractionary technology shock triggers a fall in output, employment, real wages and consumption. The figure compares the baseline calibration (exogenous unemployment benefits) to the extended one with $\phi_{U}=0.5$. The paths of the impulse response functions do not change qualitatively. However, quantitatively, there are severe differences compared to the baseline model. 
The reason for this change is due to a strong multiplier effect that emerges because of the endogeneity of unemployment compensation. The contractionary technology shock increases unemployment initially. Now, a recurrent feedback pattern occurs such that higher unemployment rates increase unemployment benefit payments. These on the other hand put upward pressure on the real wage which again increases unemployment. This feedback pattern strongly increases the inertia of the model.

The endogenous feedback between unemployment benefit payments and unemployment leads to a stronger fall in all variables except consumption. Higher unemployment compensation attenuates the fall in consumption. This is in line with the results of Fig. 1 which emphasize the positive effects of higher unemployment compensation on consumption.

\section{Structural VAR analysis}

This section addresses the empirical part. In particular, a structural vector autoregressive (SVAR) model is estimated and used to judge the macroeconomic effects of changes in unemployment benefit payments. The section starts by describing how to estimate a shock to unemployment benefit payments. I then report estimates of how major variables respond to the shock. Finally, I discuss the fraction of the variance in these variables that is accounted for by this shock.

The starting point is the characterization of the policy for unemployment benefits:

$$
\Gamma_{t}=E_{t} f\left(\Omega_{t+\tau}\right)+\epsilon_{t}^{\Gamma}, \quad \text { for some } \tau \in \mathbb{Z} \quad \text { and } \quad \epsilon_{t}^{\Gamma} \sim W N\left(0, \sigma_{\Gamma}^{2}\right)
$$

Here, $\Gamma_{t}$ represents unemployment benefit payments, $f$ is a linear function, $\Omega_{t}$ is an information set and $\epsilon_{t}^{\Gamma}$ is an exogenous shock. The basic identifying assumption is that $\epsilon_{t}^{\Gamma}$ is orthogonal to the elements in $\Omega_{t}$. Let $y_{t}$ denote the vector of variables included in the analysis. I partition $y_{t}$ as follows:

$$
y_{t}=\left[y_{1, t}^{\prime}, \Gamma_{t}\right]^{\prime}
$$

The vector $y_{1, t}$ consists of variables whose values at time $t$ are contained in $\Omega_{t}$ and that are assumed not to respond to the shock contemporaneously. The variables in $y_{1, t}$ are real gross domestic product, real consumption, real wages and unemployment. I measure unemployment benefits $\Gamma_{t}$ by the replacement rate as composed by the OECD (Martin 1996). The data sources as well as details on the replacement rate are in the "Appendix". With the exception of the replacement rate, all variables are in logarithmic terms.

The ordering of the variables in $y_{1, t}$ entails two important identifying assumptions. First, the time $t$ information set of the fiscal authority in charge of $\Gamma_{t}$ consists of current and lagged values of the variables in $y_{1, t}$. Second, the variables in $y_{1, t}$ do not respond contemporaneously to the unemployment benefits shock $\epsilon_{t}^{\Gamma}$.

The SVAR contains a constant term and four lags of each variable and the sample period is: 1971:Q1-2010:Q1. Consider the following SVAR: 


$$
(I-\Phi(L)) y_{t}=\varphi+\Psi \epsilon_{t}
$$

where $\Psi$ is a $5 \times 5$ lower triangular matrix with diagonal terms equal to unity and $\epsilon_{t}$ is a vector of mean-zero serially uncorrelated shocks with a diagonal variancecovariance matrix. I estimate the parameters $\Phi(L), \varphi, \Psi$ and the variances of the elements in $\epsilon_{t}$ using standard least-squares techniques.

\subsection{The consequences of shocks to unemployment compensation}

The impulse response functions of all variables are shown in Fig. 3. The solid black lines correspond to the point estimates for the dynamic multipliers. The shaded areas indicate confidence intervals ${ }^{4}$. Since the impulse response functions only show the adjustment paths of the variables, it is natural to ask how large the portion is that is caused by the shock to unemployment compensation. With this question in mind, Table 1 reports results for forecast error variance decompositions. In particular, it shows the percentage of the variance of the k-step-ahead forecast error in the elements of $y_{t}$ due to the exogenous shock for various horizons. The numbers in parentheses are the associated standard errors. The results suggest that after an expansionary shock to the replacement rate,

1. unemployment and real wages respond in a hump-shaped pattern peaking after about one and a half years and return slowly back to their preshock levels;

2. output responds in a hump-shaped pattern reaching a trough after about two and a half years;

3. consumption increases and falls back to its preshock value after about three years;

4. the policy shocks account for a nontrivial fraction of the variation in unemployment, real wages and consumption.

These results are qualitatively in line with those of the DSGE model discussed in Sect. 2.8 and shown in Fig. 1. Regarding the reaction of consumption to a surprise innovation in unemployment benefits, an important question addresses the issue of its strong increase. On the one hand, the increase in consumption can be due to the fact that the additional consumption expenditures of unemployed people put upward pressure on aggregate consumption. On the other hand, it can be due to the fact that higher unemployment benefits paid lead to an increase in the real wage within the wage negotiations such that finally aggregate consumption rises due to higher wages. Which of these two effects dominates? In order to answer this question, I re-run the previously estimated SVAR model, but this time without the real wage. To the extent that the previous results highlighted the importance of the real wage in transmitting the shock in unemployment benefits, the impulse response functions in a system without the real wage give a hint regarding the relative importance of the real wage in triggering reactions in aggregate consumption. The results in a SVAR system without the real wage highlight that there is no variable which is affected

\footnotetext{
${ }^{4}$ I use the method described in Sims and Zha (1999).
} 

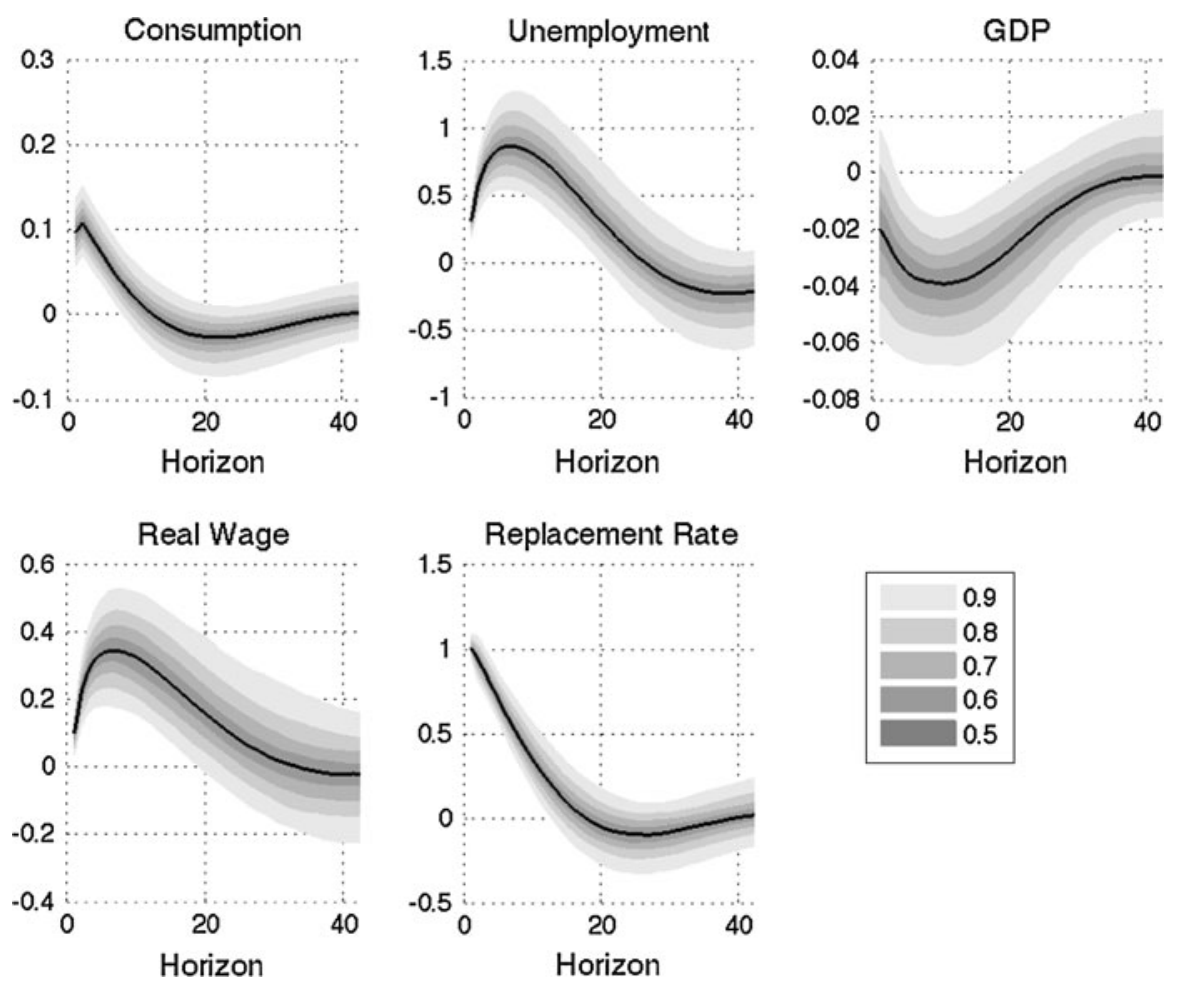

Fig. 3 Impulse response functions to a shock in the replacement rate

Table 1 Forecast error variance decomposition

\begin{tabular}{llcc}
\hline & $\begin{array}{l}\text { 4 Quarters } \\
\text { Ahead }\end{array}$ & $\begin{array}{l}\text { 8 Quarters } \\
\text { Ahead }\end{array}$ & $\begin{array}{l}\text { 32 Quarters } \\
\text { Ahead }\end{array}$ \\
\hline Output & $0.59(0.10)$ & $1.03(0.21)$ & $0.92(3.93)$ \\
Consumption & $7.25(2.12)$ & $7.63(2.41)$ & $9.01(1.89)$ \\
Unemployment & $21.37(5.31)$ & $12.51(3.11)$ & $3.01(0.19)$ \\
Real wage & $16.19(5.31)$ & $15.61(4.15)$ & $4.16(2.04)$ \\
Unemployment compensation & $54.60(13.40)$ & $62.22(19.54)$ & $82.30(27.43)$ \\
\hline
\end{tabular}

Standard errors are in parentheses

significantly. Moreover, the impulse response functions are partly even opposite to the ones shown in Fig. 3. These results highlight the importance of the real wage in transmitting shocks to unemployment compensation. Additionally, they indicate that the reason for the increase in aggregate consumption is not due to the contribution of the unemployed people who now have more cash available, but it is crucially related to the corresponding increase in the market wage due to the fact that increases in unemployment benefits put upward pressure on wages. 
As far as the transmission of the shock to unemployment benefit payments is concerned, Table 2 provides some further insights by showing results for Granger causality tests.

The coefficients in the VAR of unemployment benefits are all together, that is, for all lags considered, insignificant in the equation of any variable, except in the one of the real wage. This implies that unemployment benefits only Granger cause the real wage. Hence, the previously identified shock is a fiscal policy shock which primarily matters for the labor market since its information only helps predicting the real wage.

In this sense, the real wage is crucial in determining the pass through of unemployment benefit shocks. To the extent that it is the only variable which is Granger caused by unemployment benefits, the further propagation of this shock depends on the effects of the real wage on the other variables. As Table 2 again shows, the real wage Granger causes consumption and unemployment. Once this set of variables is affected, the surprise innovation in unemployment benefits spreads out to the remaining one: aggregate output.

Table 2 Granger causality test

\begin{tabular}{lll}
\hline Equation & Variable & $p$ Value \\
\hline Consumption & Unemployment & 0.71 \\
& Output & 0.79 \\
& Real wage & 0.03 \\
& Unemployment benefits & 0.84 \\
& All & 0.00 \\
Unemployment & Consumption & 0.02 \\
& Output & 0.01 \\
& Real wage & 0.00 \\
& Unemployment benefits & 0.89 \\
Output & All & 0.00 \\
& Consumption & 0.00 \\
& Unemployment & 0.32 \\
& Real wage & 0.57 \\
& Unemployment benefits & 0.92 \\
& All & 0.00 \\
& Consumption & 0.09 \\
& Unemployment & 0.47 \\
& Output & 0.04 \\
Unemployment benefits & Unemployment benefits & 0.00 \\
& All & 0.00 \\
& Consumption & 0.43 \\
& Unemployment & 0.05 \\
& Output & 0.95 \\
& Real wage & 0.00 \\
& All & 0.00 \\
& &
\end{tabular}


An important point to emphasize here is that despite the fact that unemployment benefits do not Granger cause labor market fluctuations along the extensive margin directly, they do cause changes in unemployment as the shock spreads out in the course of the propagation. Hence, changes in unemployment benefits as such do not directly induce changes in unemployment but only to the extent that the real wage is affected. However, once unemployment is affected by these shocks, there is a feedback. As Table 2 displays, unemployment benefits are Granger caused by unemployment and the real wage. Therefore, a VAR system having unemployment benefits entering as an exogenous variable would constitute a severe misspecification since it neglects its endogeneity. This of course raises a further question: How can we think of the shock identified by the SAVR?

\subsection{What does the shock represent?}

In general, the equation for unemployment benefits in the SVAR model can be interpreted as a reaction function in surprises of the fiscal authority. Considering the SVAR model given by Eq. 12, it becomes apparent that the equation for unemployment benefits models unemployment compensation as a function of all structural shocks in the SVAR and not just as a function of its own stochastic component. This is due to the endogeneity of unemployment benefits as already discussed by means of Granger causality tests. However, the SVAR analysis allows us to separate these stochastic structural components from each other so that we can finally analyze those elements in unemployment compensation which are uniquely due to the policy reaction function as described by Eq. 11 and separated from all other sources.

Regarding the identifying restrictions, SVAR models first decompose all endogenous variables into their expected and unexpected components. The identification procedure utilized in the current SVAR model imposes identifying restrictions only on the unexpected parts. These restrictions guarantee that the structural shocks are orthogonal to each other. Hence, given that a fiscal policy reaction function as specified by Eq. 11 is an appropriate reflection of reality, it is exactly this expression which tells us the possible sources of the policy shocks.

To this extent, there are three realistic sources: (a) changes in the relative weights defined by the fiscal authority when reacting to fluctuations in wages, unemployment, etc., (b) imperfect information on the part of the fiscal authority about the current or future economic stance and (c) changes in the fiscal policy stance unrelated to the current or future economic conditions as well as unrelated to the prevailing policy reaction function.

The first source of fiscal policy shocks refers to the decision-making process within the fiscal authority. Different fiscal policy positions on how to set unemployment benefits are likely described by different preferences concerning the relative weights determining the reaction of unemployment benefits to fluctuations in wages, unemployment, etc. Moreover, as already discussed previously, in the United States, there are two types of federal emergency programs. One is called the extended benefit program which is permanently 
authorized, meaning that the extension is triggered automatically whenever the state unemployment rate reaches a certain level. In this case, additional unemployment benefit payments are offered. The second type is a federal program that the Congress enacts temporarily during economic downturns. The Congress has repeatedly implemented these federal emergency programs. These programs typically provided benefits for a total of around 60 weeks. Their introduction as well as the duration of the implementation varies, however. As a result, the decision-making process itself can be random. In this case, the random component in the fiscal policy reaction function corresponds to random fluctuations in the preferences of the fiscal authority.

The second source of fiscal policy shocks refers to measurement errors caused by lags in the collection of the data of those variables which are essential within the fiscal authority's decision-making process. The fiscal authority can observe the actual economic stance and reverse policy actions due to measurement errors only after the final data have become available. Hence, with a fiscal reaction function based on revised data due to previous misperceptions of the economic stance, all previous policy actions show up in the SVAR model as deviations from the rule, which can then be interpreted as unexpected fiscal policy shocks ${ }^{5}$.

\subsection{Robustness}

Since a number of papers have documented the steady decline in the volatility of output, interest rates, inflation and several other macroeconomic variables for industrialized countries since the mid-1980s (see for instance McConnell and Perez Quiroz 2001), it might be possible that the responses of certain variables due to shocks differ severely in terms of their quantitative pattern across different periods.

In order to focus on this problem, I estimate the same VAR for different decades to check how sensitive the results are for specific time periods. The results of this extension highlight that despite the rather small sample size, the findings do not change qualitatively. As regards quantitative changes, the responses of the variables to unemployment benefit shocks trigger more pronounced fluctuations in the seventies and eighties while smaller ones in the following two decades.

The SVAR specification outlined in Sect. 3 has allowed for enough lags such that the reduced form residuals are clearly white noise processes. However, it is still possible that omitted variables matter for the results, since, as Francis and Ramey (2002) and Evans (1992) highlight, structural shocks might be Granger caused by other variables, among them policy variables, which impedes the interpretation of them. To check whether the identified shock is correlated with other variables, I have correlated the estimated structural disturbance with variables that a large class of general equilibrium models suggests as being jointly generated by the shock.

\footnotetext{
5 Even though these sources of shocks to policy are not intrinsically important as well as the shocks as such, the emphasize on the VAR-based approach on policy innovations arises because tracing out the dynamic adjustment paths of aggregate variables to surprise fiscal policy shocks provides a possibility of exploring the consequences of a change in the fiscal authority's stance under minimal identifying restrictions. Moreover, the analysis of structural innovations performed in SVAR models is the closest approximation of a controlled experiment available in macroeconometrics (Gottschalk 2001).
} 
Specifically, I compute correlations up to six leads and lags between the shock and the labor force participation rate, the real price of investment goods, the slope of the yield curve, the government expenditures to output ratio, the inflation rate (based on the CPI) and the oil price. In case some of these variables are trending, I adequately de-trend them. It turns out that none of the omitted variables significantly correlates with the identified structural shock.

Finally, since the identification of the structural shock is based on a recursive ordering of the variables in the SVAR, a different ordering might lead to different conclusions. In order to account for this, I allow for different contemporaneous effects of unemployment benefits on real gross domestic product, real consumption, real wages and unemployment. As it turns out, the results do not change qualitatively, even quantitatively, the alterations are negligible.

\section{Conclusion}

The previous analysis provides empirical and theoretical evidence for the fluctuations triggered by surprise innovations in unemployment benefits.

Using a standard New Keynesian model augmented with the DiamondMortensen-Pissarides model, the theoretical results highlight the importance of the labor market for the propagation of the shock in unemployment benefits. Higher unemployment benefit payments put upward pressure on the real wage which decreases the expected return of creating new jobs. Hence, aggregate employment and the amount of vacancies posted decline. As a result of the decline in employment, output decreases too; however, in contrast to this, aggregate consumption strongly increases. The reason for the increase in aggregate consumption is due to the lower real rate of interest.

Using a structural VAR model, the empirical results stress that this nonstandard fiscal policy shock primarily matters for the labor market. In particular, the identified shock affects the bargaining outcome between workers and firms and hence strongly affects the real wage. Moreover, the SVAR results highlight that due to unemployment compensation programs, resources are shifted away from their efficient use so that finally aggregate output is affected negatively. The fall is nonnegligible, however, only of rather short duration.

So far, explaining labor market fluctuations solely by macroeconomic shocks is certainly not the whole story. There are large differences in unemployment across regions, which are difficult to account for in terms of shocks hitting the whole economy uniformly rather than heterogeneously. What these findings are useful for is to figure out how macroeconomic shocks account for the common movements in unemployment and other key macroeconomic variables, but they cannot explain why different regions react so differently to aggregate shocks and why specific groups in the labor force are affected by unemployment more than others. These varieties can only be explained by focusing on individual characteristics as well as institutions governing the labor market. 
Table 3 Data: definitions and sources

\begin{tabular}{lc}
\hline$C_{t}$ & Consumption; OECD, MEI: USA Private final \\
& consumption expenditure, constant prices \\
$U_{t}$ & Unemployment level; OECD, MEI: USA Unemployment \\
& level : survey-based all persons \\
$Y_{t}$ & Gross Domestic Product; OECD, MEI: USA Gross domestic \\
& product, constant prices \\
$W_{t}$ & Real wage rate; OECD, MEI: USA Hourly wage \\
& rate: manufacturing \\
$\Gamma_{t}$ & Replacement rate; OECD, Benefits and Wages OECD \\
& Indicators: Gross replacement rates (GRR)
\end{tabular}

MEI stands for Main Economic Indicators (URL: http://oecd-stats.ingenta.com/OECD/TableViewer/ DimView.aspx ?TableName=6jmeicd.ivt\&IF_Language=eng) and EO for Economic Outlook (URL: http://oecd-stats.ingenta.com/OECD/TableViewer/DimView.aspx?TableName=4deo.ivt\&IF_Language= eng).

\section{Appendix 1: Data}

The data being used are quarterly U.S. data over the period 1971Q1:2010Q1. The series were drawn from the OECD database and from the U.S. Department of Labor (consider Table 3 for the details). These include the unemployment level (surveybased) $\left(U_{t}\right)$, real hourly earnings in the manufacturing sector $\left(W_{t}\right)$, Gross Domestic Product at constant prices $\left(Y_{t}\right)$, private final consumption expenditures at constant prices $\left(C_{t}\right)$ and the unemployment replacement rate. All variables entering the VAR are expressed in logarithmic terms except for the replacement rate. The data vector in the VAR are defined as follows

$$
\begin{gathered}
\mathbf{y}_{t}=\left[\log \left(Y_{t}\right), \log \left(C_{t}\right), \ldots\right. \\
\left.\ldots \log \left(U_{t}\right), \log \left(W_{t}\right), \Gamma_{t}\right]^{\prime}
\end{gathered}
$$

There is one important point to be mentioned regarding the time series for gross replacement rates: As noted in Martin (1996), the OECD estimates of gross replacement rates are not available on a quarterly basis. Hence, in order to equilibrate the time-series frequency of the replacement rate to a quarterly basis, I apply the method of Chow and Lin (1971) in order to temporally disaggregate the replacement rate.

\section{References}

Atkinson AB, Mickelwright J (1991) Unemployment compensation and labour market transitions: a critical review. J Econ Lit 29(4):1679-1727

Auerbach AJ, Feenberg D (2000) The significance of federal taxes as automatic stabilizers. J Econ Perspect 14(3):37-56

Baxter M, King RG (1993) Fiscal policy in general equilibrium. Am Econ Rev 83(3):315-334

Blanchard O, Perotti R (2002) An empirical characterization of the dynamic effects of changes in government spending and taxes on output. Q J Econ 117(4):1329-1368

Browning M, Crossley TF (2001) Unemployment insurance benefit levels and consumption changes. J Public Econ 80(1):1-23 
Calvo G (1983) Staggered prices in a utility-maximizing framework. J Monetary Econ 12(3):383-398

Chari VV, Kehoe PJ (1999) Optimal fiscal and monetary policy. In: Taylor JB, Woodford M (eds) Handbook of macroeconomics, 1st edn, vol 1, Chap 26. Elsevier, pp 1671-1745

Chari V, Christiano L, Kehoe PJ (1994) Optimal fiscal policy in a business cycle model. J Political Econ 102(4):617-652

Chow G, Lin A-L (1971) Best linear unbiased interpolation, distribution and extrapolation of time series by related series. Rev Econ Stat 53:372-375

den Haan WJ, Ramey G, Watson J (2000) Job destruction and propagation of shocks. Am Econ Rev 90(3):482-498

Dunson B, Maurice CS, Dwyer G (1991) The cyclical effects of the unemployment insurance program. UI occasional paper no. 91-3, U.S. Department of Labor

Ebell M, Haefke C (2009) Product market deregulation and the U.S. employment miracle. Rev Econ Dyn 12:479-504

Evans CL (1992) Productivity shocks and real business cycles. J Monetary Econ 29(2):191-208

Francis N, Ramey VA (2002) Is the technology-driven real business cycle hypothesis dead? Shocks and aggregate fluctuations revisited. NBER working paper no. 8726

Fujita S (2010) Economic effects of the unemployment insurance benefit. Federal Reser Bank Phil Bus Rev 4:20-27

Fujita S, Ramey G (2007) Job matching and propagation. J Econ Dyn Control 31:3671-3698

Galí J, López-Salido DJ, Vallés J (2007) Understanding the effects of government spending on consumption. J Eur Econ Assoc 5(1):227-270

Gertler M, Trigari A (2009) Unemployment fluctuation with staggered nash wage bargaining. J Polit Econ 117(2):38-86

Gertler M, Sala L, Trigari A (2008) An estimated monetary DSGE model with unemployment and staggered nominal wage bargaining. J Money Credit Banking 40(8):1713-1764

Gottschalk J (2001) An introduction into the SVAR methodology: identification, interpretation and limitations of SVAR models. Kiel working paper no. 1072

Gruber J (1997) The consumption smoothing benefits of unemployment insurance. Am Econ Rev 87(1):192-205

Hamermesh DS (1992) Unemployment insurance for developing countries. World Bank policy research working paper series no. 897

Lancaster T (1979) Econometric models for the duration of unemployment. Econometrica 47(4):939-956

Martin JP (1996) Measures of replacement rates for the purpose of international comparisons: a note. OECD economic studies no. 26

McConnell MM, Quiroz GP (2001) Output fluctuations in the US: what has changed since the early 80's? Am Econ Rev 90(5):1464-1476

Mortensen D, Pissarides C (1994) Job creation and job destruction in the theory of unemployment. Rev Econ Stud 61(3):397-415

Mountford A, Uhlig H (2008) What are the effects of fiscal policy shocks? NBER working paper no. 14551

Nickell S (1979) Estimating the probability of leaving unemployment. Econometrica 47(5):1249-1266

Pellizzari M (2005) Unemployment duration and the interactions between unemployment insurance and social assistance. Labour Econ 13(6):773-798

Petrongolo B, Pissarides C (2001) Looking into the black box: a survey of the matching function. J Econ Lit 39(2):390-431

Pissarides C (2000) Equilibrium unemployment theory. MIT Press, Cambridge

Sims C, Zha T (1999) Error bands for impulse responses. Econometrica 67:1113-1155

Willems T (2010) Labour market matching under imperfect information. Tinbergen Institute discussion papers no. 10-098/2

Whittaker J (2008) Extending unemployment compensation benefits during recessions. Congressional research service report RL34340

Whittaker J, Isaacs K (2011a) Unemployment insurance: legislative issues in the 112th congress. Congressional research service report R41662

Whittaker J, Isaacs K (2011b) Unemployment insurance: available unemployment benefits and legislative activity. Congressional research service report RL33362

Whittaker J, Isaacs K, Shelton A (2011) Temporary extension of unemployment benefits: emergency unemployment compensation (EUC08). Congressional research service report RS22915 